\title{
TRENDS AND STRATEGIES OF OZONE APPLICATION IN ENVIRONMENTAL PROBLEMS
}

\author{
Leonardo M. da Silva e Wilson F. Jardim* \\ Instituto de Química, Universidade Estadual de Campinas, CP 6154, 13084-971 Campinas - SP
}

Recebido em 20/4/05; aceito em 24/6/05; publicado na web em 20/1/06

\begin{abstract}
Efforts presented by the scientific community in recent years towards the development of numerous green chemical processes and wastewater treatment technologies are presented and discussed. In the light of these approaches, environmentally friendly technologies, as well as the key role played by the well-known advanced oxidation processes, are discussed, giving special attention to the ones comprising ozone applications. Fundamentals and applied aspects dealing with ozone technology and its application are also presented.
\end{abstract}

Keywords: ozone; environmentally friendly technologies; advanced oxidation processes.

\section{INTRODUCTION: POLLUTION, MODERN SOCIETY AND ENVIRONMENTALLY FRIENDLY STRATEGIES}

The increasing world population with growing industrial demands has led to a situation where protection of the environment has become a major issue and a crucial factor for several industrial processes, which will have to meet the requirements of the sustainable development of modern society ${ }^{1-5}$. In order to combine industrial activities with preservation of the environment (sustainable development), there is a tendency in most countries to adopt rigid environmental legislation where the well-known Green Technology plays a key role. In this context, chemical processes, where the best available technology (BAT) not entailing excessive cost and aspiring to performance without considerable impact, are preferred in substitution of the classical ones ${ }^{2,6}$.

This environmentally friendly strategy minimises (or even eliminates) the use or generation of hazardous substances in the design, manufacture, and application of chemical products. Approaches and principles of Green Chemistry were presented by Anastas et al. ${ }^{3}$, who discussed the terms environmentally benign chemical syntheses, alternative pathways to prevent pollution, and benign chemistry. From the above considerations, it is clear that Environmental Chemistry plays a key role in monitoring and controlling the state of the environment, thus facilitating the discovery and development of environmentally attractive technologies and, thus, "green products".

The objective of this article is to present the role played by environmental chemistry in achieving environmentally friendly strategies and to discuss the potentialities of ozone application for several types of industrial wastewaters containing recalcitrant pollutants.

\section{Pollution control and remediation}

Water pollution is a major issue for modern society. Therefore, recycling process water is a growing need for a variety of industries faced with increasing water costs and environmental constraints ${ }^{2,6}$. Several industrial finishing activities, such as printed circuit board,

*e-mail:wfjardim@iqm.unicamp.br the dying process and wood-pulp bleaching, generate large volumes of rinse water contaminated with several different inorganic and organic compounds.

Depending on water quality, final requirements and economical aspects, some processes are more suitable than others for the wastewater treatment. Physical separation of suspended solids, oils and greases, and biological treatments, have been shown to be very economical and reliable systems in the cases of municipal wastewater, food and farm processing water ${ }^{7}$. However, there are cases in which the effectiveness of these treatments drops away (e.g., soluble substances requiring physical separation, recalcitrant compounds, toxic substances for biological treatment), and, therefore, different chemical processes are used as a coadjutant in order to perform a more efficient effluent treatment ${ }^{4-6}$. Classical wastewater technologies based upon phase transfer merely concentrate the pollutants, which then have to be eliminated in a further treatment step.

According to Luck et al. ${ }^{6}$, vacuum and thermal evaporation allow recovery of high purity water in several cases but are energy intensive and expensive to operate. The efficiency of reverse osmosis depends on the type of membrane and the number of stages, but fouling problems due to salt precipitation may occur and low molar mass organic molecules show high permeabilites.

A rather innovative approach for the pollution control in wastewaters is provided by an integrated process, where the effectiveness of combining biological and physico-chemical treatments is specifically designed to be synergistic rather than additive $^{8}$. A typical example of an integrated process is the combination of chemical oxidation with activated sludge treatment, where the former is used to provide the transformation of the recalcitrant pollutants to more easily biodegradable intermediates, thus avoiding the high costs of a total mineralization ${ }^{7,9,10}$.

Chemical oxidation is considered as a complete technology for the degradation of several organics in order to meet the regulations for toxicity as well as total organic carbon (TOC) reduction, thus comprising one of the few processes which can destroy hazardous and toxic recalcitrant organics on site ${ }^{11,12}$. Besides, chemical oxidation can be more beneficial than other available treatment technologies that act by shifting the problems (hauling and landfilling) or transferring the problem to another receptor (air stripping) ) $^{13}$.

The degree to which recalcitrant organics decompose can be ascribed as ${ }^{13,14}$ : (i) primary degradation, where a structural change in the parent compound occurs, thus allowing it to be eliminated 
more easily by other processes (e.g. biological treatment, adsorption, etc.); (ii) acceptable degradation, which involves the decomposition of the parent compound to the extent that its toxicity is reduced; (iii) ultimate degradation, the last step comprising the mineralization of the organic compound (its conversion to inorganic substances such as $\mathrm{CO}_{2}$ and $\mathrm{H}_{2} \mathrm{O}$ ).

According to the literature $\mathrm{e}^{3,12,13,15}$, an environmentally acceptable oxidant should possess the following features: (i) reactivity toward the target compound; (ii) neither produce nor leave undesirable by-products during the course of the reaction; (iii) rapidly available, and (iv) reasonably inexpensive to purchase. Thus, the most commonly used oxidants for environmental applications in pollution control are ozone, hydrogen peroxide, chlorine, chlorine dioxide, sodium and calcium hypochlorite, and potassium permanganate.

According to the literature ${ }^{7}$, the combination of chemical and biological processes for wastewater treatment may result in a cheaper option for toxic wastewater treatment, where each process is affected by its individual parameters. So, chemical oxidation will be affected by the global amount of oxidizable organics, reaction rate between oxidants and organic compounds and chemical conditions such as $\mathrm{pH}$ and temperature, while biological processes are mainly affected by $\mathrm{pH}$, occurrence of toxic substances, redox potential and presence of oxygen. In this approach there are a lot of possible combinations which can be arranged for this kind of treatment and for each of them there is an optimum set-up. Also, changes in composition of the inlet effluent are easily resolved changing parameters in each of the stages, thus permitting a broad set of possibilities and a flexible design for the whole process.

\section{Advanced Oxidation Processes, AOP}

Oxidation processes comprising the use of the hydroxyl radical, $\mathrm{HO}^{\circ}-E^{\circ}=2.80 \mathrm{~V}$, as the main oxidant constitute the wellknown Advanced Oxidation Processes (AOP $)^{4,13}$. AOP are a promising alternative technology in pollution control for several different contaminated effluents, and the performance of the different combined AOP-systems, such as, $\mathrm{O}_{3} / \mathrm{H}_{2} \mathrm{O}_{2}, \mathrm{UV} / \mathrm{H}_{2} \mathrm{O}_{2}, \mathrm{Fe}^{2+} /$ $\mathrm{H}_{2} \mathrm{O}_{2}$ (Fenton's reagent), UV/O, $\mathrm{UV} / \mathrm{TiO}_{2}$ (heterogeneous photocatalysis), etc., has been discussed in the literature by several authors ${ }^{4,16-27}$. A recent review dealing with alternative technologies for wastewater treatment involving application of several different AOP systems has been reported by Gogate and Pandit ${ }^{16}$

In the special case of AOP involving ozone application, literature reports have pointed out some considerations involved in wastewater treatment ${ }^{16,28}$. For example, in the case of ozone-based systems (e.g. $\left.\mathrm{O}_{3} / \mathrm{H}_{2} \mathrm{O}_{2} ; \mathrm{O}_{3} / \mathrm{UV}\right)$ it must be ensured that $\mathrm{O}_{2}$ is not depleted during the course of the reaction, since the $\mathrm{HO}_{2} / \mathrm{O}_{2}{ }^{-}$radicals liberated in the various peroxyl radical reactions generate further $\mathrm{HO}$ radicals by the rapid reaction of $\mathrm{O}_{2}{ }^{-}-$with $\mathrm{O}_{3}$.

The $\mathrm{O}_{3} / \mathrm{H}_{2} \mathrm{O}_{2}$-system is one the most practical since it only involves hydrogen peroxide addition into an ozonated solution. In this case multistage injection systems are another recent invention, reported to yield much better results as compared to conventional operation. Apart from using reactors in series, the addition of hydrogen peroxide or ozone can be adjusted in increasing steps depending on the concentration of the remaining pollutants as well as the oxidation products.

As a rule, AOP efficiencies depend on the chemical nature of the effluent subjected to the treatment, such as, $\mathrm{pH}$, turbidity, chemical oxygen demand (COD) and the presence of radical scavengers. A project aiming at evaluation of the economic viability of AOP for a given acceptable level of contaminants was described by Luck et al. ${ }^{6}$.

\section{OZONE TECHNOLOGY: TRENDS AND STRATEGIES}

Costs associated with ozone production have dropped by $50 \%$ in the last decade and, therefore, a great number of new industrial applications has appeared in recent years ${ }^{29}$. Potential markets for ozone technology exist especially in water treatment, surface sterilisation, wood pulp bleaching, materials processing, treatment of textile wastewater, and treatment of cooling water ${ }^{30-32}$. An important aspect of ozone application in water treatment is its use as disinfectant in purified water loops for the pharmaceutical and electronic industries ${ }^{33,34}$. Besides, it is worthwhile to mention that ozone application, unlike that of chlorine, does not leave harmful residues such as haloforms after reaction ${ }^{35}$. So, the environmental advantages of ozone over chlorine justify its higher cost of generation for an increasing number of applications.

Ozone is sparingly soluble in water $\left(12 \mathrm{mg} \mathrm{dm}^{-3} ; 25{ }^{\circ} \mathrm{C}\right)$ and its behaviour in aqueous media can be evaluated by examining $\mathrm{O}_{3}$ decomposition kinetics. Once ozone enters into water, it becomes highly unstable and rapidly decomposes through a complex series of reactions ${ }^{36-39}$. According to the literature ${ }^{38,39}$, ozone decomposition in water can be described as follows:

$$
\begin{aligned}
& \mathrm{O}_{3}+\mathrm{HO}^{-} \rightarrow \mathrm{HO}_{2}^{-}+\mathrm{O}_{2}^{-\cdot} \\
& \mathrm{HO}_{2}^{\cdot} \leftrightarrow \mathrm{O}_{2}^{-}+\mathrm{H}^{+} \\
& \mathrm{O}_{3}+\mathrm{O}_{2}^{-\cdot} \rightarrow \mathrm{O}_{3}^{-\cdot}+\mathrm{O}_{2} \\
& \mathrm{O}_{3}^{-\cdot}+\mathrm{H}^{+} \rightarrow \mathrm{HO}_{3}^{-} \\
& \mathrm{HO}_{3}^{\cdot} \rightarrow \mathrm{HO}^{\cdot}+\mathrm{O}_{2} \\
& \mathrm{HO}^{+}+\mathrm{O}_{3} \rightarrow \mathrm{HO}_{4}^{\cdot} \\
& \mathrm{HO}_{4}^{\cdot} \rightarrow \mathrm{HO}_{2}^{\cdot}+\mathrm{O}_{2}^{\cdot} \\
& \mathrm{HO}_{4}^{\cdot}+\mathrm{HO}_{4}^{\cdot} \rightarrow \mathrm{H}_{2} \mathrm{O}_{2}+2 \mathrm{O}_{3} \\
& \mathrm{HO}_{4}^{\cdot}+\mathrm{HO}_{3}^{\cdot} \rightarrow \mathrm{H}_{2} \mathrm{O}_{2}+\mathrm{O}_{3}+\mathrm{O}_{2}
\end{aligned}
$$

According to this mechanism hydroxide ions $\left(\mathrm{HO}^{-}\right)$initiate a chain of reactions when ozone enters into water. The chain reaction is sustained by $\mathrm{HO}_{2}{ }^{\circ}$ formation via step II, which can then initiate further reactions. The hydroxyl radical $\left(\mathrm{HO}^{\circ}\right)$ is the most important species formed during ozone decomposition. Thus, ozone can react in an aqueous medium directly with substrates, such as molecularozone, or indirectly, via radical-intermediates formed during ozone decomposition in aqueous media. Thus, depending on the ozone behaviour in the aqueous medium, the selectivity of ozonation can be high (direct reaction) or low (indirect reaction) ${ }^{36,37}$.

Since the HO radical is not selective and possesses a very high oxidative potential, this species is therefore a much more effective oxidant than ozone itself. Depending on the influence of the partial pressure of the dissolved oxygen, the following semi-reactions are representative of the standard redox potentials ${ }^{40,41}$ :

$\mathrm{O}_{3}+6 \mathrm{H}^{+}+6 \mathrm{e}^{-} \rightarrow 3 \mathrm{H}_{2} \mathrm{O}$

$$
\begin{aligned}
E^{\circ} & =1.51 \mathrm{~V} \\
E^{\circ} & =2.07 \mathrm{~V}
\end{aligned}
$$

$\mathrm{O}_{3}+2 \mathrm{H}^{+}+2 \mathrm{e}^{-} \rightarrow \mathrm{H}_{2} \mathrm{O}+\mathrm{O}_{2}$

According to these semi-reactions, even in cases where the reaction represented by Equation 2 is considered, the hydroxyl radical is by far a stronger oxidant than ozone.

\section{Ozone application in water treatment}

Water is the source of life and its availability is decreasing, thus making obvious the need for treatment of water resources ${ }^{42}$. In the industrialised countries improvements in water treatment have led to a near eradication of acute health hazards caused by water-borne diseases ${ }^{42,43}$. 
Since the discovery of ozone by Schönbein ${ }^{44}$ in 1840 , this oxidant has been much used for water purification, due to its strong bactericide activity. The employment of ozone for the purification of water on an industrial scale was first suggested by Werner Siemens in 1889 , but it took another ten years to actually employ ozone commercially to provide a pure water supply for cities and villages surrounded by contaminated areas ${ }^{45}$.

The first experiment on water disinfection via ozonation was carried out by De Meritens in 1886. Since then, there has been a great interest in the use of ozone as a viable alternative to chlorine in water disinfection in order to eliminate the formation of hazardous by-products, such as, trihalomethanes and organochlorine compounds ${ }^{46,47}$. The production of drinking water requires the removal of numerous compounds (e.g. humic substances and toxic micropollutants) and ozone acts by oxidising several drinking water contaminants, comprising different organic and inorganic compounds, as well for eliminating pathogenic micro-organisms (e.g. viruses, parasites $)^{46,48}$.

According to the U.S. Environmental Protection Agency (EPA), ozone is the most powerful disinfectant available ${ }^{49}$. The Safe Drinking Water Act of 1996 presents proposed rules for presence of disinfection by-products (DBPs), such as haloacetic acids and trihalomethanes, which arise from disinfection of organic pollutants by chlorine and other halogens. The presence of these compounds in a water supply creates health risks for population. Thus, the elimination of DPB through alternative methods of disinfection is desirable, and therefore the use of ozone as an oxidant and disinfectant for the treatment of water and wastewater is gaining popularity.

According to the literature ${ }^{48}$, the main drawback associated with ozone application in drinking water production is the presence of the bromide ion. Thus, to attain the levels required by environmental legislation both $\mathrm{O}_{3}$-dosage and residence time during water treatment should be previously evaluated in cases where raw water contains bromide ions in order to maintain the bromate formed during ozonation at concentrations lower than $10 \mathrm{mg} \mathrm{dm}^{-3}\left(\mathrm{BrO}_{3}^{-}\right.$is a potential carcinogen).

Characterisation of raw waters for the ozone application was reported by Park et al. ${ }^{50}$, who investigated the effects of particulates, ozone load, and sequential ozone injection. This study revealed ozonation is a very efficient technology for potable water treatment. According to Foller and Kelsall ${ }^{30}$, the amount of ozone required for potable water treatment, depending on the volumetric flow rate and the intrinsic properties of the raw water, varies from $0.005 \mathrm{~kg}$ day $^{-1}$ (those requiring small quantities) up to 50 to $5000 \mathrm{~kg} \mathrm{day}^{-1}$.

The ozonation kinetics plays a key role in the feasibility of treating organic compounds present in water. Since the work of Hoigné et al. ${ }^{51-54}$ rate constants for several different compounds in aqueous media have been measured ${ }^{55,56}$. Differences related with the direct (via ozone) or indirect (via radical) nature of the ozonation process were presented by Yao and $\mathrm{Haag}^{47}$, who reported the direct ozonation kinetics for several contaminants whose maximum contaminant level values (MCL) have been established by the U.S. Environmental Protection Agency (EPA). The differentiation between the two oxidative pathways is important since it permits evaluation of the nature of the product types in different natural waters, and application of the rate constants to other systems, including biological media ${ }^{46,47}$. In general, compounds presenting pseudo second order kinetic rate constant, $k$, higher than $100 \mathrm{~L}$ $\mathrm{mol}^{-1} \mathrm{~s}^{-1}$ will be consumed significantly by either direct ozonation and via indirect processes, while compounds presenting a strong recalcitrant nature $\left(k<<100 \mathrm{~L} \mathrm{~mol}^{-1} \mathrm{~s}^{-1}\right)$ will be destroyed mainly by the hydroxyl radical.

\section{Treatment of heavily contaminated effluents}

Several applications for ozonation and related AOP in wastewater treatment are available ${ }^{5,13,15,16,57}$. Examples of the use of ozone to degrade organic contaminants in wastewaters are pulp and paper production, shale oil processing, production of pesticides, dye manufacture, textile dying and pharmaceutical production. Two important applications, the treatment of effluents from the textile industry and from pulp and the paper mills, are discussed below.

(i) Textile wastewaters - Textile waste effluents are one of the wastewaters that are very difficult to treat satisfactorily because they are highly variable in composition and contain several different recalcitrant compounds ${ }^{39,58,59}$. Wastewaters that are generated at various stages of the dyeing process differ in compositions and temperature. The high pollution load is mainly caused by spent dyeing baths. Their constituents are unreacted dyeing compounds, dispersing agents (surfactants), salts and organics washed out of the material which undergoes dyeing ${ }^{39}$. Based on the EPA's toxic release inventory, approximately 2200 ton of four hazardous dyes are discharged annually into publicity owned treatment works ${ }^{60}$.

The classical methods employed for treating textile wastewaters include various combinations of the biological (activated sludge), physical and chemical processes ${ }^{61,62}$. Dye molecules are highly structured polymers, hence very difficult to break down biologically and cannot be treated efficiently by an activated sludge process or any combination of biological, chemical coagulation and physical methods ${ }^{58,63}$. Besides, the main drawback of these processes is the generation of a large amount of sludge or solid waste, resulting in high operational costs for sludge treatment and disposal ${ }^{64}$.

Different alternative technologies for textile wastewater treatment involving ozone application have been proposed in the literature ${ }^{16,32,59}$. A comparative study on oxidation of dispersed dyes by electrochemical processes, ozone, hypochlorite and Fenton's process was reported by Szpyrkowicz et al..$^{39}$ Combinations of these alternative technologies with the classical methods already mentioned permit obtaining a very good decolouration and COD reduction of the textile wastewater to meet discharge requirements.

In the special case of ozone application the ozonation efficiency depends on the total organic carbon present in the effluent. For low strength dye waste effluents, ozonation alone is sufficient to totally eliminate the colour and reduce the turbidity ${ }^{16,59}$. However, for medium and high strength waste effluents, ozonation is found to be sufficient to reduce the colour, but not enough to reduce the turbidity. Hence, coagulation of the textile effluent using aluminium sulphate $\left(\sim 60 \mathrm{mg} \mathrm{dm}^{-3}\right.$ for a TOC value of $\left.\sim 600-1000 \mathrm{ppm}\right)$ or especially designed polymers will be necessary ${ }^{58,59}$. As reported by Tzitzi et al. ${ }^{59}$, ozonation of the wastewater after coagulationprecipitation process, under the same conditions as the raw wastewater ozonation, exhibited more efficient decolouration (>90\%) and COD reduction (> 30\%), while the biodegradability was found to increase.

After the initial degradation via alternative oxidative processes, the residual organic carbon generated during partial mineralization can be further effectively degraded using the activated sludge process. Thus, the combination of ozonation with proper chemical coagulation and an activated sludge process is a promising alternative technology for dealing with textile industry effluent, which reduces sludge disposal and meet the requirements.

The degradation of dyes used in the textile industry using various AOP has been reported in the literature ${ }^{39,65}$. According to Shu and Huang ${ }^{65}$, who investigated the chemical oxidation of nonbiodegradable azo dyes by ozonation and photo-oxidation proces- 
ses in a pilot scale photochemical UV-ozone reactor, the UV-light did not significantly enhance the degradation ability of the ozonation reaction.

(ii) Pulp and Paper mill wastewaters - A very large amount of coloured pollutant compounds (200 to $300 \mathrm{~kg} \mathrm{ton}^{-1}$ of pulp), mainly chlorolignin, is produced during the conventional bleaching of softwood kraft pulp ${ }^{57,66}$. Most of these compounds have a high molar mass $(>1 \mathrm{kDa})$ and are resistant to conventional biological degradation, requiring, therefore, an alternative technology for wastewater treatment. Development of new technologies for wastewater treatment of pulp and paper mills is a very important issue due to the urgent necessity to meet current environmental legislation ${ }^{67}$. Therefore, special attention has to be paid to the socalled "Totally Chlorine Free Technologies", which comprise the use of alternative oxidative processes in substitution of $\mathrm{ClO}_{2}$ in order to provide a better, safer, effluent treatment ${ }^{68}$.

Ozone is a current technology that has matured and demonstrated its possibilities as an efficient and economically sound chemical to be used in advanced effluent treatment in the pulp and paper industry ${ }^{29,67,69}$. In fact, the use of advanced effluent treatment in the pulp and paper industry comprising the combination of ozone with fixed bed biofilm reactors is one of the most efficient tertiary effluent treatment processes to give maximum elimination of COD, colour and AOX (Absorbable Organic Halogens) with a minimum of ozone dosage. This technology provides an effective elimination of polluting and disturbing substances (instead of merely separating them as is done with precipitation) and transfers the oxidative residue into a small amount of biological excess sludge.

Ozone diffusion parameters, i.e., bubble size and distribution, reaction time and hydrodynamic pattern, are decisive for interface/ film or bulk reaction, thus becoming the key economic factor for the elimination of certain kinds of organic matter by transferring persistent "hard" COD into biodegradable compounds as measured by the biological oxygen demand (BOD). The results of laboratory batch and pilot tests of different mill effluents, presented by Helbe et $a l .^{29}$, revealed biological effluent treatment with relatively low BOD concentration after the ozonation requires biofilm technologies, i.e., biofilters, for the further biological treatment, since classical biological processes such as activated sludge systems cannot be operated well with this expected low loaded effluent. Also, if COD removal efficiencies higher than 50\% are required, advanced treatment with ozone and biofiltration must be undertaken in two stages. Pilot tests with COD removal efficiencies higher than $80 \%$ were achieved with specific ozone consumption of 0.6 to $0.8 \mathrm{~kg} \mathrm{O}_{3} / \mathrm{kg}$ COD eliminated after biofilters. Cost analysis revealed the added costs for a paper mill represent an increase on the order of $1 \%$ of the manufacturing cost of the paper.

Other potential ozone applications in wastewater treatment Ozone may also be used with several different wastewaters containing organic wastes (e.g. phenolic compounds) and pesticides $^{57,70,71}$. The treatment and removal of these compounds are among the main goals of the water and wastewater treatment industries and, as a result, constant advances are being made to improve the technologies of removal.

The literature dealing with the ozonation of more than 30 pesticides was reviewed by Reynolds ${ }^{72}$, who reported that organophosphorus insecticides are generally more readily oxidised by ozonation than are organochlorine pesticides, while most organonitrogen and phenolic pesticides are readily oxidised via ozonation processes.
Biodegradability - When ozonation is placed upstream of biological filtration, and environmental conditions such as dissolved oxygen, $\mathrm{pH}$ and temperature are favourable, microbiological activity is increased in the filter and biodegradability of dissolved organic carbon is enhanced ${ }^{49}$. Ozone addition not only increases the biodegradability of the dissolved organics, but also introduces large amounts of oxygen to the water, thus creating an excellent environment for biological growth on the filter media. The advantages of biologically active filtration in most U.S. plants using ozone was discussed by the U.S. Environmental Protection Agency ${ }^{49}$.

In the case of heavily contaminated effluents containing a considerable amount of recalcitrant organics, that a biodegradability enhancement of the effluent is necessary before its introduction into the biological reactor ${ }^{73}$. Ozonation processes are very effective in partially oxidising organics in the effluent to biodegradable compounds that can be removed by biologically active filtration.

Different studies involving the investigation of biodegradability enhancement for several different industrial effluents after ozone application have been reported in the literature ${ }^{10,73}$. Rationalisation of the results presented in these studies permitted concluding that the biodegradability enhancement after ozone application depends on several parameters: (i) intrinsic properties of the effluent to be treated; (ii) reaction time, and (iii) ozone load. In the light of this consideration, these variables play a key role in biodegradability enhancement and, therefore, optimisation of the operating conditions adopted in the effluent treatment is necessary in order to attain the biodegradability requirements.

\section{Ozone generation: corona process versus electrochemical technology}

Because ozone is highly reactive and cannot be stored over an extended period of time, it has to be generated on site. According to the literature ${ }^{4,5,13,31,40}$, ozone can be generated "in situ" using the following technologies: (i) Photochemistry (UV-radiation); (ii) Corona (silent electric discharge) and the (iii) Electrochemistry (electrolysis of aqueous solutions).

The most common technology for the ozone production is the Corona process, where a dry gas, either air or pure oxygen, is subjected to a silent electrical discharge ${ }^{5,40,45}$. In this case a reaction between the oxygenated species $\left(\mathrm{O}^{*}+\mathrm{O}_{2}\right)$, assisted by the free energetic electrons that are created from an electric spark, occurs in the gas phase, generating the $\mathrm{O}_{3}$-molecule. Although this technology requires a lower specific power consumption $(\sim 10 \mathrm{~W} \mathrm{~h}$ $\left.\mathrm{g}^{-1}\right)$ the concentration of the $\mathrm{O}_{3}$ in the gaseous phase $\left(\mathrm{O}_{2}+\mathrm{O}_{3}\right)$ is low ( 2.5 to $7.5 \mathrm{wt} \%)$, thus restricting its use in environmental applications involving recalcitrant pollutants.

Ozone generation can be also performed via Photochemical technology, where pure oxygen or air, when irradiated by the UV light inside a photochemical reactor, produces ozone in a small quantity. As reported previously ${ }^{5}$, Photochemical Ozone Generation (POG) presents a very high specific energy demand $\left(\sim 1 \mathrm{~kW} \mathrm{~h} \mathrm{~g}^{-1}\right)$ due its low efficiency and, therefore, it is very expensive when compared with the conventional Corona process. Since the POG technology presents very good reproducibility, due to easy control of the rate of ozone production by controlling the lamp source power (e.g. low pressure mercury lamp, $\lambda=185 \mathrm{~nm}$ ), it is very suitable for producing ozone in small amounts, as required for laboratory purposes, odour elimination, etc.

Several studies show that Electrochemistry is a promising alternative technology for "in situ" ozone generation ${ }^{5,30,32,40,74-77}$. Electrochemical Ozone Production (EOP) presents a couple of features that are not achieved with the Corona process, thus making 
it an interesting alternative for several ozone applications: (i) investment costs (per unit mass of produced $\mathrm{O}_{3}$ ) are considerably lower than for the conventional Corona technology and (ii) concentrations of $\mathrm{O}_{3}$ in the product gas that can be achieved are higher.

Several technological advances related to EOP were achieved in recent decades ${ }^{5,13,30,32,40,74-77}$. Electrolytic ozonizers based on solid polymer electrolyte technology (SPE), which operate in electrolytefree water and under ambient temperature conditions, permit ozone application directly into water streams ready for various oxidising and/or disinfectant applications. In this case the total energy demand is minimised, since $\mathrm{O}_{3}$-production is conduced at ambient temperature (refrigeration is not necessary) and the high ozone mass transfer rate avoids the accessories such as gas diffusers and pumping systems $\mathrm{s}^{30,32,76}$. Stucki et al.$^{32,76}$ developed a reactor based on the SPE-technology, which was employed in a purified water plant in the pharmaceutical industry. The reactor proved to be efficient for disinfecting more than $15 \mathrm{~m}^{3} \mathrm{~h}^{-1}$ of water with an energy demand of $\sim 60 \mathrm{Wh} \mathrm{g}^{-1}$.

Other promising technology for $\mathrm{O}_{3}$-generation is based on electrolytic ozonizers using specially designed electrolytes. In this case the cathodic process is the reduction of the oxygen present in the air and, as a consequence, the specific energy demand is very close to that presented by a conventional Corona device ${ }^{30}$. This technology furnishes a very high efficiency $(\geq 35 \%)$, which makes this electrochemical ozonizer rather competitive with the corona technology in several different applications where a higher $\mathrm{O}_{3}$ concentration in the gaseous phase is necessary. The main drawback associated with this ozonizer system is that employment of a gas diffuser system is necessary.

\section{Ozone applications in engineering systems}

An ozonation reactor is at least a two phase system, consisting of the gas phase containing ozone and the fluid or product phase (generally contained in a liquid), where the ozone must be adequately transferred for chemical reaction ${ }^{29}$. In the case of mixed gas-liquid reactors, the absolute partial pressure of ozone is the main design parameter. So, the mixing energy and whether this energy has a macroscopic, or turbulent, or a microscopic, or laminar, character as well as the hydrodynamic pattern (complete-mix, plugflow, cocurrent, countercurrent) of the ozonation reactor, are the main design and control parameters for the task assigned to ozone ${ }^{15}$.

An ozonation system consists of four components ${ }^{78}$ : (i) feed gas preparation system; (ii) ozone generator; (iii) gas-liquid contactor (reactor system), and (iv) off-gas treatment system. Each of these components adds to ozonation costs and, therefore, optimisation of these individual parameters is always necessary. The main parameters to be adjusted are the $\mathrm{O}_{3}$-concentration and the ozone mass transfer rate, which is related with components (ii) and (iii), respectively. Attempts have also been made to combine processes involving different AOP (e.g. $\mathrm{O}_{3} / \mathrm{UV}$ and $\left.\mathrm{O}_{3} / \mathrm{H}_{2} \mathrm{O}_{2}\right)$ to standard ozonation systems in order to reduce the ozone load ${ }^{57}$.

Influence of the ozone mass transfer on water treatment Effectiveness of ozone as either a disinfectant or an oxidant is affected by ozone reaction kinetics and the ozone mass transfer rate from the gas phase to the liquid phase $\mathrm{e}^{59,71,79}$. So, the ozonation process depends considerably on partial ozone concentration in the gaseous phase $\left(\mathrm{O}_{2} / \mathrm{O}_{3}\right)$ and the ozone mass transfer rate. While the former is limited by the ozone generator system, the later depends on ozone distribution in the liquid phase provided by the gas-liquid contactor system.
The most effective way to increase the ozone mass transfer rate is to increase the interfacial area available for mass transfer by decreasing the size of the gas bubbles dispersed in solution and increasing their residence time. Thus, the mass transfer rate will be a maximum when a given mass of the gaseous mixture $\left(\mathrm{O}_{2} / \mathrm{O}_{3}\right)$ is introduced in the liquid forming a great number of very small bubbles, thus increasing to a maximum the reaction zone area located in the gas/liquid interface ${ }^{71}$. In this case, the two important parameters for the gas-liquid contactor mixed-gas reactor are the gas-liquid dispersion volume, $V$ and the gas-liquid specific contact area, $a$. The value of $a$ is related to the gas volume fraction (void fraction), $\varepsilon$, and the Sauter mean bubble diameter, $d_{\mathrm{s}}$, of the gas.

If the gas phase consists of $N$ spherical bubbles of different diameters, $d$, then ${ }^{80}$ :

$$
a=\frac{N \pi\left\langle d^{2}\right\rangle}{V}
$$

where $\left\langle d^{2}\right\rangle$ is the average of the squares of the diameters. Similarly, the volume of the gas is given by the relation:

$\varepsilon V=\frac{N \pi\left\langle d^{3}\right\rangle}{6}$

Consequently, the specific contact area $a$ is given by:

$a=\frac{6 \varepsilon\left\langle d^{2}\right\rangle}{\left\langle d^{3}\right\rangle}=\frac{6 \varepsilon}{d}$

The importance of the bubble size distribution in the liquid phase is obtained by analysing Equation 5, which shows that $a$ is inversely proportional to the average bubble size of the dispersed gas. From a theoretical point of view, the average bubble size depends not only on the properties of gas and liquid but also, to a large extent, on mechanisms responsible for the breaking up and mutual coalescence of bubbles, that is, on reactor hydrodynamics ${ }^{80}$.

Gas-liquid contactors currently used in water and wastewater systems include submersible orifices, such as, nozzles, sinteredmetal or sintered-glass plates, sprinklers, rubber membranes and electrostatic spraying microbubble generators ${ }^{71,81,82}$. In combination with these bubble generation system devices, providing mechanical agitation can be used to increase the contact between phases ${ }^{62,80,83}$. Such devices provide kinetic energy to the bulk fluid in order to provide efficient bubble dispersion.

The use of gas diffusers in tanks under pressure promotes operational conditions with a very high efficiency, thus reducing the $\mathrm{O}_{3}$-dosage and contact time. On the contrary, open tanks (under atmospheric pressure) present a lower disinfectant efficiency when compared with pressurised tanks and present considerable $\mathrm{O}_{3}$ losses to the atmosphere (utilisation efficiency of ozone $<<100 \%$ ).

The concentration of ozone generated using the Corona process is so low that the transfer efficiency to the liquid phase is an extremely important consideration ${ }^{84}$. For this reason, very deep and covered contact chambers are normally used, where the mixture $\mathrm{O}_{2} / \mathrm{O}_{3}$ is generally diffused from the bottom of the chamber in fine bubbles that provide mixing of the wastewater as well as achieving maximum ozone mass transfer and utilisation.

In conventional processes the gas utilisation efficiency can be improved by linking reactors in series or by using a compressor to recirculate the unreacted gas back into the processing liquid ${ }^{62}$. Both 
of these processes are complex, requiring additional devices such as sparged loop reactors, surface aerators, and the gas-induced reactor, which are basically constituted of a hollow shaft and impeller, or a standpipe with several different types of impellers. In order to avoid the utilisation of these devices, Hsu et al. ${ }^{83}$ developed a new gas-induced reactor consisting of two in-series $45^{\circ}$ pitched-blade turbines mounted in a draft tube. Two main characteristics of this device include gas induction and bubble recirculation around the draft tube in the liquid, thus increasing the time for bubble residence in solution. This technology strongly promotes an improvement in ozone utilisation. A more recent investigation conducted by these authors ${ }^{62}$, involving ozone application for treatment of solutions containing textile dyes using their gas-induced reactor, revealed that ozone utilisation efficiency during decomposition of textile dyes can be higher than $90 \%$ using proper agitation speeds.

In a gas-liquid interface, where gas absorption is followed by an irreversible chemical reaction (e.g. degradation reaction), two steps control the overall reaction rate: (i) the mass transfer from the gas phase to the liquid phase and (ii) the chemical reaction in the liquid process. Thus, the ozonation process can be represented as follows:

$\mathrm{O}_{3(\mathrm{~g})} \rightarrow \mathrm{O}_{3(1)}$ (mass transfer step)

$\left[\mathrm{O}_{3(\mathrm{l})} \Leftrightarrow \Sigma(\mathrm{Rad})_{(\mathrm{l})}\right]+v X_{(\mathrm{l})} \rightarrow$ Products $_{(\mathrm{l})}$ (degradation step)

where: $\mathrm{O}_{3(\mathrm{~g})}$ and $\mathrm{O}_{3(\mathrm{l})}$ represent the ozone present in the gaseous and liquid phase, respectively; $\left[\mathrm{O}_{3(1)} \Leftrightarrow \Sigma(\mathrm{Rad})_{(1)}\right]$ describes the $\mathrm{O}_{3}$ decomposition which yields oxygenated free radicals; $v$ is the stoichiometric coefficient, and $X$ is a given target compound.

According to Equations 6.1 and 6.2, the efficiency of degradation via ozonation depends considerable on the ozone mass transfer rate and the $\mathrm{O}_{3}$-decomposition rate. The simplest and most commonly used model to treat this gas-liquid system is the film theory ${ }^{85}$, where it can be considered, assuming that the oxygen/ozone mixture is not very soluble in water, that no mass transfer limitation is observed within the gas phase and only the liquid phase mass transfer resistance needs to be considered. In this context, it is feasible to assume that there is a liquid film of average thickness, $d_{L}$, between the liquid bulk and the gas-liquid interface. Also, the mass transport is at a steady-state within the film and, therefore, there is no mass accumulation.

Figure 1 shows a simplified sketch representative of a gas-liquid interface where the film theory can be applied.

According to the sketch presented in Fig. 1, an elementary bubble surface region constitutes a gas/liquid interface, which comprises the reaction zone (RZ). According to the literature ${ }^{80,85}$, both the RZ-thickness and the ozone concentration profile $\left(\left[\mathrm{O}_{3}\right]\right.$ vs. distance) depend on the nature of the chemical reaction occurring at the outer surface of the gas phase.

In the light of the film model, the nature of the chemical reaction can be analysed by two limiting cases corresponding to slow and fast reactions. The film theory is mainly based on two dimensionless parameters, namely, the Hatta number $(\mathrm{Ha})$ and the enhancement factor $\left(E_{\mathrm{j}}\right)$, which describe the different phenomena occurring in the reaction zone ${ }^{80,85}$.

From a theoretical point of view if the ozonation is characterised as Slow $\left(H a<0.3\right.$ and $\left.E_{\mathrm{i}}=1\right)$ the reaction rate is controlled by chemical reactions $\left(\mathrm{O}_{3}\right.$-diffusion in the film region is not important). In this case, the ozone concentration in the film region suffers a slight decrease and the chemical reaction remains in the more external region of the film, which can be denoted by $d_{1}$ (see Fig. 1).
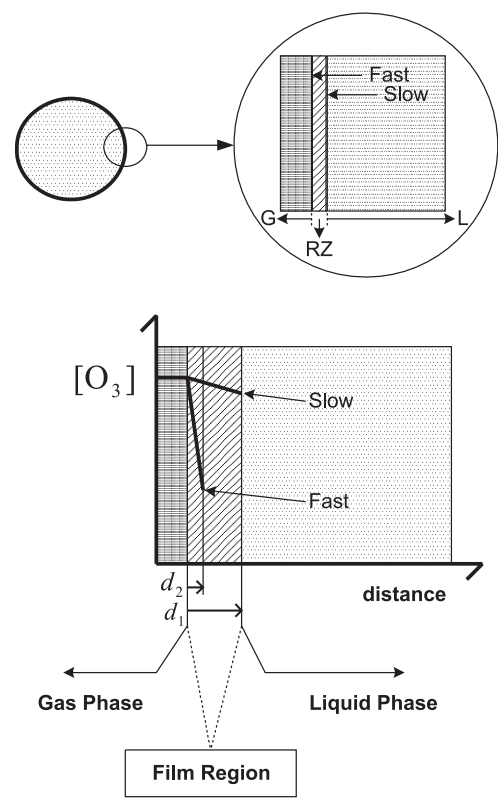

Figure 1. Scheme representative of a gas-liquid interface where the film theory is applied

On contrast, if the reaction is characterised as Fast $\left(\mathrm{Ha}>3\right.$ and $E_{\mathrm{i}}$ $>1$ ) the reaction rate is limited by the ozone mass transfer rate. In this case the ozone concentration suffers a strong depletion in the film region, which possesses a thickness represented by $d_{2}$.

Intermediate cases where $0.3<H a<3$ are representative of ozonation reactions where both chemical kinetics and the mass transfer rate are important. A model for this intermediate case was recently presented by Benbelkacem and Debellefontaine ${ }^{85}$, who validated their model experimentally by investigating the ozonation of fumaric acid in a semi-batch bubble column reactor. According to these authors the ozonation of fumaric acid occurs mainly within the film region.

Because ozone and/or hydroxyl radical react with several recalcitrant organics very rapidly, from a practical point of view the ozone mass transfer rate is very important for several different degradation processes ${ }^{65,86}$. Studies dealing with the ozonation of effluents of the textile industry reveal that ozone mass transfer controls the degradation reaction rate, presenting rates for the $\mathrm{O}_{3}$ mass transfer in the $0.245 \times 10^{-3}$ to $0.774 \times 10^{-3} \mathrm{mg} \mathrm{mol} \mathrm{dm}^{-3} \mathrm{~s}^{-1}$ interval ${ }^{65}$. Depending on the efficiency presented by the gas diffuser system $^{71,80}$, the average size of microbubbles changes from 0.2 to $4.0 \mathrm{~mm}$. In a continuous ideally stirred tank reactor (CISTR), where the reaction mixture is considered to be uniform throughout the tank, any increase in the $\mathrm{O}_{3}$-mass transfer rate will lead to an increase in CISTR performance.

An efficient mass transfer rate also significantly decreases $\mathrm{O}_{3}$ dosage as a consequence of the increase in the ozone utilisation efficiency and the increase in the decomposition rate of the pollutants or pathogenic micro-organism dispersed in the contaminated aqueous medium. In the case of ozonation of potable water, for a given dosage the initial ozone demand (i.e. the amount of ozone required before its concentration reaches saturation) uses efficient diffusers leading to a high $\mathrm{O}_{3}$-mass transfer, ensuring a very good decontamination efficiency.

From the above discussion, may be observed that the use of ozone in water and wastewater treatment strongly depends on optimisation of the amount of the ozone added into the liquid phase (nominal load) and the contact time, which, by means of a reactor 
tank, will permit the effective load to be as close as possible of the nominal ones $\left(\mathrm{O}_{3}\right.$-residual $\left.\approx 0\right)$. The optimal operating conditions can be achieved in practice by means of an automated system using devices that permit maintaining rigid control of the residual ozone ${ }^{48}$. Other variables are controlled in order to obtain optimal operational conditions: (i) water (effluent) flow rate; (ii) $\mathrm{O}_{3}$-concentration in the gaseous phase and (iii) the ozone load. Specific software especially developed for optimisation of these variables is available where, for a considered pollutant charge distributed in a particular effluent, it is possible to optimise the diffuser system, ozone load and the choice of the ozone generator and the reactor tank ${ }^{48}$.

Degradation kinetics under constant ozone load in solution In several applications (e.g. degradation of textile dyes) a fast zeroorder $\mathrm{O}_{3}$-dissolution is observed before the system has reached a saturated ozone concentration ${ }^{64}$. In these cases, the saturation condition in the aqueous phase is reached for a given $\mathrm{O}_{3}$-load and the chemical reaction is the rate determining step of the overall process.

Since the oxidising ability of the ozonation process comes from both molecular ozone and the hydroxyl free radical, the rate of disappearance (degradation) of organics proceeds as a multi-step reaction. This processes can be represented by following scheme, representative of the oxidation pathways of the degradation process via ozonation:

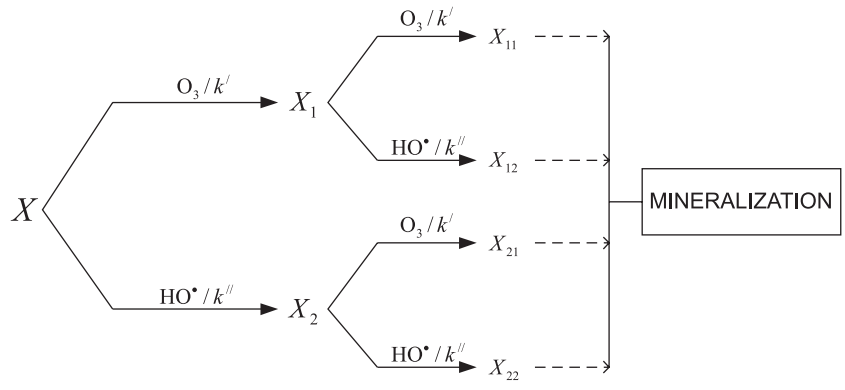

According to this scheme, the extension of the degradation process (degree of mineralization) will be sustained by continuous $\mathrm{O}_{3}$ and/or $\mathrm{HO}$ attacks on the daughter products represented by $X_{\mathrm{ij}}$.

Considering the destruction of the parent compound, $X$, via ozonation the reaction rate may be expressed as follows ${ }^{64,71}$ :

$\frac{\mathrm{d}[X]}{\mathrm{d} t}=-\left\{k^{\prime}[X]\left[\mathrm{O}_{3}\right]+k^{\prime \prime}[X]\left[\mathrm{HO}^{\bullet}\right]\right\}$

where: $[X]$ is the concentration of the parent compound; $\left[\mathrm{O}_{3}\right]$ and $\left[\mathrm{HO}^{*}\right]$ are the concentrations of ozone and the hydroxyl radical, respectively; $k^{\prime}\left(=n_{1} k_{1}\right)$ and $k^{\prime \prime}\left(=n_{2} k_{2}\right)$ are the apparent kinetic rate constants comprising the product of the stoichiometric coefficients $(n)$, which reflect oxidations of daughter products, and the actual rate constant $\left(k_{1}\right.$ and $\left.k_{2}\right)$.

According to eq. 7 , a slow degradation kinetics depends considerably on the total concentration of the effective oxidants present in solution $\left(\mathrm{O}_{3}\right.$ and/or $\left.\mathrm{HO}^{*}\right)$. Also, the competition of direct and indirect kinetic pathways will depend on $\mathrm{pH}$ and on the presence of free radical scavengers (e.g. carbonate). For example, Chu and $\mathrm{Ma}^{64}$ showed that the presence of free radical scavengers decreased the ozonation efficiency of recalcitrant organics present in textile industry effluent.

A mathematical model representative of ozonation of textile industry wastewater was proposed by Tzitzi et al..$^{59}$, where was assumed that the total organic carbon present in the textile effluent comprises coloured and uncoloured organics. Theoretical analysis of these reactions revealed, using readily measurable parameters (absorbance, COD and residual liquid ozone concentration), that the reaction model may be successfully used for design of appropriate ozonation reactors for textile wastewater pre-treatment ${ }^{59}$.

\section{CONCLUSIONS AND FUTURE DEVELOPMENTS}

Development and optimisation of alternative technologies for pollution control in different contaminated environments comprise an important issue in modern society, which deserves special attention from the scientific community. In this context, ozone, which is a powerful oxidant, can be looked upon as an effective substitute for chorine and its derivatives in several applications.

Ozone can be used as an efficient source of the hydroxyl radical in solution and therefore be employed in several different Advanced Oxidation Processes. Potentialities presented by ozone justify its production cost in several applications involving treatment of wastewater containing recalcitrant compounds, which are normally not treated using conventional biological and physical processes.

Ozone application in wastewater treatment is a promising technology and its efficiency depends on optimisation of several operating conditions: (i) ozone distribution in the liquid phase using specially designed diffuser systems; (ii) ozone concentration in the gaseous phase $\left(\mathrm{O}_{2} / \mathrm{O}_{3}\right)$; (iii) nominal ozone dosage, and (iv) contact time. The optimal conditions for ozone applications can be achieved in practice by means of an automated system using devices that permit maintaining rigid control of the residual ozone leaving the effluent. This experimental approach provides an optimum balance between the ozone production rate and the costs associated with the total energy dispensed in the whole process. As a consequence, it is hoped that ozone losses may be considerably minimised, thus making Ozone Technology very attractive from an economic point of view for several different applications.

Ozone is commercially generated using, principally, Corona technology. However, considering that any increase in ozone production efficiency increases the degradation rate of pollutants, Electrochemical technology oriented for ozone production is a promising alternative in several applications where a high $\mathrm{O}_{3}$ concentration is required.

\section{ACKNOWLEDGEMENTS}

L. M. da Silva and W. F. Jardim wish to thank the FAPESP Foundation. The authors also thank Dr. C. Collins for revising the manuscript.

\section{REFERENCES}

1. Jüttner, K.; Galla, U.; Schmieder, H.; Electrochim. Acta 2000, 45, 2575.

2. Armor, J. N.; Appl. Catal., A 1999, 189, 153.

3. Anastas, P.; Williamson, T.; Green Chemistry, Theory and Practice, Oxford University Press: Oxford, 1998.

4. Domènech, X.; Jardim, W. F.; Litter, M. I. In Eliminación de Contaminantes por Fotocatálisis Heterogénea; Blesa, M. A., ed.; Digital Grapfic: La Plata, Argentina, 2001.

5. da Silva, L. M.; Santana, M. H. P.; Boodts, J. F. C.; Ouim. Nova 2003, 26, 880

6. Luck, F.; Djafer, M.; Vel Leitner, N. K.; Gombert, B.; Legube, B.; Water Sci. Technol. 1997, 35, 287.

7. Marco, A.; Esplugas, S.; Saum, G.; Water Sci. Technol. 1997, 35, 321.

8. Scott, J. P.; Ollis, D. F.; Environ. Prog. 1995, 14, 88.

9. Jochimsen, J. C.; Jeckel, M. R.; Water Sci. Technol. 1997, 35, 337.

10. Lopez, A.; Ricco, G.; Mascolo, G.; Tiravanti, G.; Di Pinto, A. C.; Passino, R.; Water Sci. Technol. 1998, 38, 239.

11. Jr. Eckenfelder, W. W.; Industrial Water Pollution Control, $2^{\text {nd }}$ ed., McGraw-Hill Inc.: New York, 1989, p. 300. 
12. Bowers, A. R.; Toxicity Reduction in Industrial Effluents, Lankford, P. W.; Eckenfelder, W. W. Jr., eds.; Van Nostrand Reinhold: New York, 1990, p. 247.

13. Tatapudi, P.; Fenton, J. M. In Environmental Oriented Electrochemistry; C. A. C. Sequeira, ed., Elsevier: Amsterdam, 1994, p. 104.

14. Scow, K. M. In Handbook of Chemical Property Estimation Methods; Lyman, W. J.; Reehl, W. F.; Rosenblatt, D. H., eds.; McGraw-Hill Inc.: New York, 1982

15. Hoigné, J.; The Chemistry of Ozone in Process Technologies for Water Treatment, Plenum-Press: New York, 1988.

16. Gogate, P. R.; Pandit, A. B.; Adv. Environ. Res. 2004, 8, 553.

17. Jardim, W. F.; Huang, C. P. In Proceedings of the Sixth International Symposium on Chemical Oxidation: Technology for the Nineties; Eckenfelder, W. W.; Bowers, A. R.; Roth, J. A., eds.; Technomic Publishing Co.: Lancaster, 1996.

18. Nogueira, R. F. P.; Alberici, R. M.; Jardim, W. F. In ref. 17.

19. von Sonntag, C.; Dowideit, P.; Fang, X.; Mertens, R.; Pan, X.; Schuchmann, M. N.; Schuchmann, Heinz-Peter; Water Sci. Technol. 1997, 35, 9.

20. Balcioglu, I. A.; Arslan, I.; Sacan, M. T.; Environ. Technol. 2001, 22, 813.

21. Ormad, P.; Cortes, S.; Puig, A.; Ovelleiro, J. L.; Water Res. 1997, 31, 2387.

22. De, A. K.; Bhattacharjee, S.; Dutta, B. A.; Ind. Eng. Chem. Res. 1997, 36, 3607.

23. Emílio, C. A.; Jardim, W. F.; Litter, M. I.; Mansiella, H. D.; J. Photochem. Photobiol., A 2002, 151, 121.

24. Alberici, R. M.; Jardim, W. F.; Appl. Catal., B 1997, 14, 55.

25. Nogueira, R. F. P.; Jardim, W. F.; Sol. Energy Matter. Sol. Cells 1996, 56, 471.

26. Nogueira, R. F. P.; Jardim, W. F.; J. Adv. Oxid. Technol. 1999, 4, 1.

27. Ziolli, R. L.; Jardim, W. F.; J. Photochem. Photobiol., A 2003, 155, 243

28. Flaherty, K. A.; Huang, C. P. In Chemical Oxidation; Eckenfelder, W. W.; Bowers, A. R.; Roth, J. A., eds.; Technomic Inc.: Lancaster, 1992, vol. 2, p. 58.

29. Helbe, A.; Schlayer, W.; Liechti, P. A.; Jenny, R.; Möbius, C. H.; Water Sci. Technol. 1999, 40, 343.

30. Foller, P. C.; Kelsall, G. H.; J. Appl. Electrochem. 1993, 23, 996.

31. Slavinskaya, G. V.; Selemenev, V. F.; Russ. J. Appl. Chem. 2003, 76, 1472

32. Stucki, S.; Baumann, H.; Christen, H. J.; Kötz, R.; J. Appl. Electrochem. 1987, 17, 773 .

33. Setz, W.; Pharm. Ind. 1985, 47, 15.

34. Nebel, C.; Netzgod, W. W.; Solid State Technol. 1984, 27, 185.

35. Wojtenko, I.; Stinson, M. K.; Field, R.; Crit. Rev. Environ. Sci. Technol. 2001, 31, 295.

36. Miller, R. E.; J. Org. Chem. 1961, 26, 2327.

37. Butkovic, V.; Klasin, L.; Orhanovic, M.; Turk, J.; Güsten, H.; Environ. Sci. Technol. 1983, 17, 546.

38. Hoigné, J. In Handbook of Ozone Technology and Applications; Rice, R. G.; Netzer, A., eds.; Ann Arbor Science: Michigan, 1982, p. 341.

39. Szyrkowicz, L.; Juzzolino, C.; Kaul, S. N.; Water Res. 2001, 35, 2129.

40. Foller, P. C.; Tobias, W.; J. Electrochem. Soc. 1982, 129, 506.

41. Zoubov, N.; Pourbaix, M. In Atlas of Electrochemical Equilibria in Aqueous Solutions; M. Pourbaix, ed.; NACE International: Texas, 1974, p. 540 .

42. Grimm, J.; Bessarabov, D.; Sanderson, R.; Desalination 1998, 115, 285

43. Pieterse, M. J.; Water SA 1989, 15, 169.

44. Schönbein, C. F.; C. R. Hebd. Seances Acad. Sci. 1840, 10, 706

45. Perkin, F. M.; Trans. Faraday Soc. 1908, 4, 81.

46. Camel, V.; Bermond, A.; Water Res. 1998, 32, 3208

47. Yao, D. C. C.; Haag, W. R.; Water Res. 1991, 25, 761.

48. Albícker, C. A.; Agua Latinoam. 2002, 2, 30.
49. EPA; Alternative Disinfectants and Oxidants Guidance Manual, Office of Water, US Environmental Protection Agency: Washington, D.C., 1999.

50. Park, H-S.; Hwang, T-M.; Kang, J-W.; Choi, H.; Oh, H-J.; Water Res. 2001, $35,2607$.

51. Hoigné, J.; Bader, H.; Water Res. 1976, 10, 377.

52. Hoigné, J.; Bader, H.; Water Res. 1983, 17, 173.

53. Hoigné, J.; Bader, H.; Water Res. 1983, 17, 185.

54. Hoigné, J.; Bader, H.; Haag, W. R.; Staehelin, J.; Water Res. 1985, 19, 993.

55. Pryor, W. A.; Giamalva, D. H.; Church, D. F.; J. Am. Chem. Soc. 1984, 106, 7094.

56. Neta, P.; Huie, R. E.; Ross, A. B.; J. Phys. Chem. 1988, 17, 1027.

57. Masten, S. J.; Davies, S. H. R.; Environ. Sci. Technol. 1994, 28, 180.

58. Sheng, H. L.; Chi M. L.; Water Res. 1993, 27, 1743.

59. Tzitzi, M.; Vayenas, D. V.; Lyberatos, G.; Water Sci. Technol. 1994, 29, 151.

60. EPA; Toxics Release Inventory, Public Data Release, Office of Pollution Prevention and Toxics, US Environmental Protection Agency: Washington, D.C., 1995.

61. Lin, S. H.; Chen, M. L.; Water Res. 1997, 31, 868.

62. Hsu, Y-C.; Chen, J-T.; Yang, H-C.; Chen, J-H.; AIChE J. 2001, 47, 169.

63. Lin, S. H.; Lai, C. L.; Water Res. 2000, 34, 763.

64. Chu, W.; Ma, Chi-Wai; Water Res. 2000, 34, 3153.

65. Hung-Yee, S.; Ching-Rong, H.; Chemosphere 1995, 31, 3813.

66. Libergott, N.; van Lierop, B.; Nolin, A.; Faubert, M. G.; Laflamme, J. K.; Pulp Paper Can. 1991, 92, 84.

67. Möbius, C. H.; Abwasser der Papier und Zellstoffindustrie, $2^{\text {nd }}$ ed., Munchen, 1997.

68. Meng, M. X.; Hsieh, J. S.; Tappi J. 2000, 83, 67.

69. Möbius, C. H.; Water Sci. Technol. 1999, 40, 11.

70. Hawash, S.; El-Ibiari, N.; El-Diwani, G.; Waste Mgmt. 1990, 10, 269.

71. Shin, Won-Tae; Mirmiram, A.; Yiacoumi, S.; Tsouris, C.; Sep. Purific. Technol. 1999, 15, 271.

72. Reynolds, G.; Ozone: Sci. Eng. 1989, 11, 339.

73. Hao, O. J.; Kim, H.; Chiang, P. C.; Crit. Rev. Environ. Sci. Technol. 2000, 30,449

74. da Silva, L. M.; de Faria, L. A.; Boodts, J. F. C.; Electrochim. Acta 2003, 48,699

75. da Silva, L. M.; de Faria, L. A.; Boodts, J. F. C.; Pure Appl. Chem. 2001, $73,1871$.

76. Stucki, S.; Theis, G.; Kötz, R.; Devantay, H.; Christen, H. J.; J. Electrochem. Soc. 1985, 132, 367.

77. Scott, K.; Electrochemical Processes for Clean Technology, The Royal Society of Chemistry: Cambridge, 1995.

78. Ferguson, D. W.; Gramith, J. T.; McGuire, M. J.; J. Am. Water Works Assoc. 1991, 83, 32

79. Sharna, M. M.; Trans. Inst. Chem. Eng. 1993, 71, 595.

80. Westerterp, K. R.; Wijngaarden, R. J. In Ullmann's Encyclopedia of Industrial Chemistry; Elvers, B.; Hawkins, S.; Schulz, G., eds.; $5^{\text {th }}$ ed., VCH Publishers: Cambridge, 1992 vol. B4.

81. Zaky, A. A.; Nosseir, A.; J. Phys. D: Appl. Phys. 1977, 10, L189.

82. Smith, J. S.; Valsaraj, K. T.; Thibodeaux, L. J.; Ind. Eng. Chem. Res. 1996, $35,1688$.

83. Hsu, Y-C.; Chen, J-T.; Yang, H-C.; Chen, J-H.; AIChE J. 1996, 42, 3146.

84. Tchobanoglous, G.; Burton, F. L. In Wastewater engineering: treatment, disposal, and reuse; Clark, B. J.; Morriss, J. M., eds.; $3^{\text {rd }}$ ed.; Metcalf and Eddy, Inc.; Singapore, 1991.

85. Benbelkacem, H.; Debellefontaine, H. Chem. Eng. Process. 2003, 42, 723.

86. Saunders, M. F.; Gould, P. J.; Southerland, R. C.; Water Res. 1983, 17, 1407. 